\title{
Guidance materials from 2014 to 2019 on nutritional care for Ebola patients in Ebola Treatment Units: an analysis
}

\author{
Mija Ververs ${ }^{1, *}$ (1) and Cecilia Vorfeld ${ }^{2}$ \\ 'Emergency Response and Recovery Branch, Division of Global Health Protection, Center for Global Health, \\ Centers for Disease Control and Prevention, 2500 Century Boulevard NE, Mailstop E-22, Atlanta 30345, GA, USA: \\ ${ }^{2}$ Medicine, Science and Humanities, Johns Hopkins University, Baltimore, MD, USA
}

Submitted 6 February 2020: Final revision received 26 June 2020: Accepted 30 June 2020: First published online 20 August 2020

\begin{abstract}
Objective: To evaluate the inclusion and exclusion of nutritional content in guidance materials related to nutritional care for hospitalised Ebola Virus Disease (EVD) patients of any age with the aim to provide recommendations for future revised nutritional care guidelines in Ebola Treatment Units (ETU).

Design: Qualitative and quantitative analyses of ETU protocols and other guidance materials were conducted. Materials were obtained from practitioners, their organisations and governments active in EVD outbreaks since 2014.

Setting: Guinea, Liberia, Sierra Leone and Democratic Republic of Congo.

Results: Guidance materials showed a wide variety of topics. Most contained information on different feeding phases during illness, the use of specialised products, what and how to feed children aged 0-23 months, and meal and snack frequency for different age groups. Most materials lacked guidance on how to assess or accommodate patients' dietary preferences, how to obtain feedback on nutritional care from patients or how to assess whether patients need feeding support. These aspects are particularly relevant to prevent deterioration of the patients' nutritional status. There was limited guidance on operational aspects of food preparation and provision.

Conclusions: Since 2014, numerous materials have been developed by organisations and governments on nutritional support in ETU. Although every EVD outbreak response must be contextualised because of the complexity of EVD and its case management, it is important to resolve technical differences and to provide comprehensive and more practical guidance. The findings of this study may inform future revised guidelines from normative UN organisations and governments of countries affected by EVD.
\end{abstract}

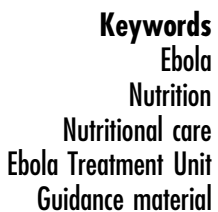

words

Nutrition a Treatment Unit Guidance material
On 1 August 2018, the Ministry of Health of the Democratic Republic of Congo reported a new outbreak of Ebola virus disease (EVD). This is the 10th and largest Ebola outbreak in Democratic Republic of Congo, and the second-largest outbreak of Ebola ever recorded since the virus was discovered in 1976 in Democratic Republic of Congo ${ }^{(1)}$. In 2019, a review was conducted on experiences and lessons learned from practitioners on the operational aspects of nutritional care and support in Ebola Treatment Units (ETU) in the 2014-2016 West Africa and current Democratic Republic of Congo EVD outbreak with the ultimate aim to improve current and future responses ${ }^{(2)}$. The review also evaluated the use and usefulness of the 2014 Interim Guidelines on providing nutritional support to patients in ETU that were issued by the WHO, the UN Children's Fund (UNICEF) and the World Food Programme in November $2014^{(3)}$. These guidelines aimed to address nutritional needs and optimal nutritional care in the current Ebola crisis, with a particular focus on the practical aspects of the care within ETU for EVD patients. One of the reviews' findings was that while the technical aspects of the 2014 Interim Guidelines were acceptable, its feasibility was questioned as it did not provide sufficient practical applications.

Since 2014, various non-governmental organisations, the Red Cross/Red Crescent Movement, UN agencies and governments have been directly involved in the care for EVD patients in the ETU. Many developed their own EVD outbreak nutritional care protocols and/or other 
guidance materials identifying best practices on the provision of food, including the method of preparation and distribution, what to provide to patients and how. Some materials addressed what was lacking in the 2014 Interim Guidelines and/or contextualised its guidance to their place of work. This study evaluates what topics were present or absent in guidance materials related to nutritional care for hospitalised EVD patients of any age. The aim is to provide recommendations on which topics to include in future revised guidelines on nutritional care in ETU from normative UN organisations and governments.

\section{Methodology}

This study took place in June and July 2019 and examined guidance materials retrieved from practitioners, their organisations and governments that are or have been active in the EVD outbreaks.

Practitioners engaged in the nutritional care in the ETU and who participated in a previous investigation ${ }^{(2)}$ were approached to share their materials they used, which were developed to guide nutritional care in ETU by their respective organisations or by others (see Ref. (2) how practitioners were selected). Guidance materials that were stand-alone documents or part of larger protocols were included as long as they aimed to provide guidance on nutritional care. In addition, publicly accessible guidance materials were also evaluated. An initial screening of all materials by the authors resulted in a list of most common themes and sub-themes of all instructions found in the guidance materials. A second, more detailed analysis scored each document to indicate whether any instruction on a given theme was present or absent. Mentioning the sub-theme was sufficient to get a 'present' score, even if instructions lacked details. Scores were initially assigned by one author (C.V.) and independently verified by another (M.V.) author. Discrepancies were discussed and resolved. As scientific evidence on the best nutritional care in EVD patients is limited and lacks consensus $^{(4)}$, no analysis was conducted to evaluate the accuracy of the instructions.

\section{Results}

Eighteen different documents were retrieved ${ }^{(3,5-21)}$ : three in French $^{(16-18)}$ and fifteen in English. Only three were publicly available on the Internet ${ }^{(3,20,21)}$. Eight were from non-governmental organisations and the Red Cross/Red Crescent Movement ${ }^{(5-12)}$ of which one was co-authored by two different organisations ${ }^{(11)}$. Six were from governments (mostly Ministries of Health) with or without support from the $\mathrm{UN}^{(13-18)}$, and four were from UN agencies (WHO, UNICEF and World Food Programme $)^{(3,19-21)}$. One guidance document was removed from analysis as it did not
Table 1 List of organisations and governments that provided guidance materials on nutritional support for Ebola patients in Ebola treatment units

\begin{tabular}{|c|c|}
\hline & $\begin{array}{l}\text { Number of } \\
\text { documents } \\
\text { provided }\end{array}$ \\
\hline \multicolumn{2}{|l|}{ Non-governmental organisations } \\
\hline GOAL International & 1 \\
\hline International Medical Corps (IMC) & 1 \\
\hline Médecins Sans Frontières (MSF) & 1 \\
\hline Partners in Health & 1 \\
\hline Save the Children & 1 \\
\hline \multicolumn{2}{|l|}{ Red Cross/Red Crescent Movement } \\
\hline International Committee of the Red Cross (ICRC) & 1 \\
\hline $\begin{array}{l}\text { International Federation of Red Cross and Red } \\
\text { Crescent Societies (IFRC) }\end{array}$ & 1 \\
\hline \multicolumn{2}{|l|}{ Governments } \\
\hline Government of Sierra Leone & 1 \\
\hline $\begin{array}{l}\text { Ministry of Health and Social Welfare Republic of } \\
\text { Liberia }\end{array}$ & 1 \\
\hline $\begin{array}{l}\text { République Démocratique du Congo Ministère de } \\
\text { la Santé Publique }\end{array}$ & 3 \\
\hline \multicolumn{2}{|l|}{ United Nations (UN) organisations } \\
\hline United Nations Children's Fund (UNICEF) & 1 \\
\hline World Health Organization (WHO) & 2 \\
\hline $\begin{array}{l}\text { World Health Organization (WHO), United Nations } \\
\text { Children's Fund (UNICEF), World Food } \\
\text { Programme (WFP) (co-authored) }\end{array}$ & 1 \\
\hline \multicolumn{2}{|l|}{ 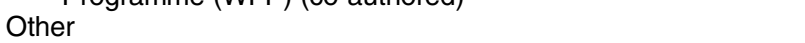 } \\
\hline $\begin{array}{l}\text { International Committee of the Red Cross (ICRC) } \\
\text { and Médecins Sans Frontières (MSF) } \\
\text { (co-authored) }\end{array}$ & 1 \\
\hline Total & 17 \\
\hline
\end{tabular}

specifically refer to nutritional care in ETU ${ }^{(15)}$. Table 1 presents the list of the organisations and governments and the included materials.

Table 2 summarizes a list of all instruction topics found in the guidance materials and a percentage of guidelines where these topics were included (see online supplementary material, Supplemental Table for detailed results).

More than half of the guidance materials (59\%) contained clarifications of principles of treatment in relation to nutrition.

\section{Ebola virus disease and feeding phases/groups}

Around two-thirds provided descriptions of different feeding phases during illness (71\%) and feeding groups related to consistency of foods (liquid, semi-solid and sold) (65\%).

\section{Assessment of patients with Ebola virus disease}

Around one-third of materials provided instructions on how to assess patients' nutritional status, and $71 \%$ advised on patients' appetite assessment. There were only two documents with instructions on pregnant or lactating women and their nutritional needs. Only four documents (24\%) included assessments on the need for physical feeding support, for the critically ill and/or paediatric cases. 
Table 2 Topics listed in guidance materials on nutritional care for Ebola patients in Ebola treatment units and the frequency of topic inclusion ${ }^{(3,5-14,16-21)}$

Nutritional Care Guidance Materials for Ebola Patients in Ebola

Treatment Units

No. mentioning

this topic

Validity of guidance document

Date/year of publication

Contains a statement of validity of document and its

(n 17)

(1) recommendations

Purpose of guidance document

Clarification on the principles of treatment of EVD in relation to nutritional care and needs

EVD and feeding phases/groups

Description of disease and feeding phases

a) Affecting nutritional intake

b) Causing specific nutritional needs

c) Different feeding phases (maintenance, boost, transitions)

Description of different feeding groups (consistency: solid, semisolid and liquid)

Assessment of patients with Ebola virus disease

Instructions on whether and how to assess a patient's dietary needs
a) Pregnant and lactating women
b) Consistency adjustments
c) Appetite
d) Assistance with feeding (feeding support)

Instructions on how to assess a patient's nutritional status

Algorithm guiding nutritional care options (assessment tool)

14

1

10

Ebola virus disease

Advice on energetic needs

Food products

a) Recommending use of specialised products ${ }^{*}$

b) Rationale on use of specialised products

c) Instructions on what food products to avoid and why

d) Instructions on how to improve palatability of ORS, CSB etc.

Specific guidance on how to and what to feed
a) Infants $<6$ months
b) Children 6-23 months

Instructions on whether or how to use NGT feeding

Instructions on quantities of food/drinks needed per patient for different age groups
a) $<6$ months
b) 6-23 months
c) 24-59 months
d) Older children
e) Adults

Instructions on meal and snacks frequency for different age groups

Information on interactions of certain drugs used on EVD

treatment and food/drinks

Instructions on night-time feeding

Instructions on whether and how to monitor patient's food/drink intake

Intake of specific nutrients

Advice on need for provision of specific nutrients
a) Protein
b) Vitamin $A$
c) Vitamin $\mathrm{C}$
d) $\mathrm{Na}$
e) $\mathrm{K}$
f) $\mathrm{Ca}$
g) $\mathrm{Mg}$
h) $P$
i) $\mathrm{Zn}$

j) Others (e.g. multivitamins, vitamin $\mathrm{K}, \mathrm{Fe}$ )

Symptoms of Ebola virus disease that affect nutritional care and status

Instructions on how to deal with specific symptoms and dietary

intake/needs

a) Nausea

b) Vomiting 
Table 2 Continued

\begin{tabular}{|c|c|c|}
\hline $\begin{array}{l}\text { Nutritional Care Guidance Materials for Ebola Patients in Ebola } \\
\text { Treatment Units }\end{array}$ & $\begin{array}{l}\text { No. mentioning } \\
\text { this topic } \\
(n 17)\end{array}$ & $\%$ \\
\hline c) Diarrhoea & 6 & 35 \\
\hline d) Severe dehydration & 7 & 41 \\
\hline e) Hypoglycaemia & 3 & 18 \\
\hline f) Hypokalaemia & 3 & 18 \\
\hline \multirow{2}{*}{\multicolumn{3}{|c|}{$\begin{array}{l}\text { Food preparation and distribution } \\
\text { Food preparation }\end{array}$}} \\
\hline & & Food preparation \\
\hline a) Instructions on preparation of specific food/drinks & 11 & 65 \\
\hline b) Instructions on how to organise food preparation & 9 & 53 \\
\hline $\begin{array}{l}\text { c) Instructions on how to organise quality control measures if } \\
\text { food preparation is outsourced }\end{array}$ & 1 & 6 \\
\hline \multicolumn{3}{|l|}{ Instructions on how to provide food to individual patients } \\
\hline a) Packaging & 3 & 18 \\
\hline b) Allocation system & 2 & 12 \\
\hline c) Which utensils & 11 & 65 \\
\hline d) Advice on temperature & 4 & 24 \\
\hline $\begin{array}{l}\text { Instructions on specific advice for families if they want to bring } \\
\text { meals for a patient }\end{array}$ & 4 & 24 \\
\hline \multicolumn{3}{|l|}{ Instructions on how to organise feeding support } \\
\hline a) Who gives the feeding support & 9 & 53 \\
\hline b) How to provide feeding support & 10 & 59 \\
\hline c) Physical feeding support aids & 5 & 29 \\
\hline \multicolumn{3}{|l|}{ Instructions on how to calculate } \\
\hline a) Number of meals needed in an ETU & 3 & 18 \\
\hline b) Food/drink supplies for an ETU & 3 & 18 \\
\hline $\begin{array}{l}\text { c) Feeding support needs for patients (hardware and human } \\
\text { resources) }\end{array}$ & 0 & 0 \\
\hline $\begin{array}{l}\text { Instructions on how to safely transport food from outside and } \\
\text { within ETU to patients }\end{array}$ & 2 & 12 \\
\hline $\begin{array}{l}\text { Instructions on how to set up the food system to provide } \\
\text { nutritional care for EVD patients }\end{array}$ & 5 & 29 \\
\hline $\begin{array}{l}\text { Instructions on how to handle leftover food and utensils from bed } \\
\text { site }\end{array}$ & 11 & 65 \\
\hline \multicolumn{3}{|l|}{ Patient's preferences } \\
\hline $\begin{array}{l}\text { Instructions on how to assess/accommodate for patient's dietary } \\
\text { preferences }\end{array}$ & 7 & 41 \\
\hline $\begin{array}{l}\text { Instructions on how to obtain patient's feedback on nutritional } \\
\text { care during stay in ETU }\end{array}$ & 3 & 18 \\
\hline \multicolumn{3}{|l|}{ Malnutrition and/or anthropometry } \\
\hline $\begin{array}{l}\text { Instructions on if, when and how to conduct anthropometric } \\
\text { measurements }\end{array}$ & 12 & 71 \\
\hline $\begin{array}{l}\text { Instructions on whether or how to adjust treatment for } \\
\text { malnourished patient with EVD }\end{array}$ & 4 & 24 \\
\hline \multicolumn{3}{|l|}{ Discharge } \\
\hline $\begin{array}{l}\text { Instructions on discharge procedures and food provision for } \\
\text { recovery }\end{array}$ & 11 & 65 \\
\hline \multicolumn{3}{|l|}{ Job instructions } \\
\hline $\begin{array}{l}\text { Job descriptions of various roles in the nutritional care for EVD } \\
\text { patients }\end{array}$ & 5 & 29 \\
\hline \multicolumn{3}{|l|}{ Forms } \\
\hline \multicolumn{3}{|l|}{ Patient forms related to nutrition } \\
\hline a) Assessment & 5 & 29 \\
\hline b) Monitoring & 7 & 41 \\
\hline c) Meal calculations & 4 & 24 \\
\hline
\end{tabular}

EVD, Ebola Virus Disease; ETU, Ebola Treatment Unit; ORS, oral rehydration salt; NGT, naso-gastric tube.

${ }^{\star}$ Ready-to-use therapeutic foods, high-energy biscuits, therapeutic milk, ready-to-use supplementary foods and/or corn soy blend (CSB).

\section{General management, diet and feeding of children and adults with Ebola virus disease}

Fifty-nine percent contained advice on energetic needs of patients in an ETU. All materials recommended the use of specialised products (therapeutic milk, ready-to-use therapeutic food, corn soy blend, etc.), of which $82 \%$ explained some rationale behind the recommendation.
Many materials (76\%) had instructions on what to feed children aged 0-23 months and how, and contained instructions on meal and snack frequency for different age groups. However, instructions on quantities of food and drinks needed per patient for each age group were more limited (47-65\%). Seventy-one percent contained instructions on whether to use, and if so, how to use naso-gastric 
tube feeding for patients in ETU. Older guidance materials developed during the West Africa outbreak were more restrictive on using naso-gastric tube. Eighteen percent had instructions on how to improve the palatability or acceptability of products, for example, oral rehydration salts (ORS), corn soy blend. Almost half of the guidance materials advised to avoid certain products. In some cases, use of sugary carbonated drinks and (fruit) juices were discouraged $^{(3,18)}$. However, advice in favour of use of (fruit) juices was found in some materials from humanitarian organisations. WHO's pocketbook gave contradictory advice on the same issue ${ }^{(20)}$. Few guidance materials (29\%) contained information on whether and how to monitor patients' food/drinks intake or instructions on night-time feeding.

\section{Intake of specific nutrients}

Advice on the need for provision of specific nutrients varied and mostly included K (53\%), Zn (41\%), and to some extent, protein (35\%). Less than one-fifth mentioned vitamin $\mathrm{A}$.

\section{Symptoms of Ebola virus disease that affects nutritional care and status}

A few guidance materials ( $<20 \%$ ) gave instructions on how to deal with specific symptoms and dietary intake or needs related to, for example, nausea, vomiting, hypoglycaemia and hypokalaemia. More information was provided on diarrhoea (35\%) and severe dehydration (41\%).

\section{Food preparation and distribution}

Guidance on the operational aspects of food preparation and distribution to patients in an ETU varied. Concerning food preparation, 53-65\% gave some instructions on preparation of specific food/drinks and how to organise it. From previous work, it is known that half of the food preparation was outsourced to catering companies ${ }^{(2)}$, yet only one document contained instructions on how to organise quality control measures related to outsourced food preparation. Except for guidance on which eating or drinking utensils to use, there were limited instructions on how to provide food to individual patients (e.g. packaging, allocation system) or how to deal with meals offered by families (12-24\%). Over half (53-59\%) provided instructions on how to organise feeding support and by whom though no document gave guidance on how to calculate, for example, human resources requirements for this. Limited guidance $(<20 \%)$ was given on how to calculate the number of meals and supplies, taking into account the different consistencies of patients' meals. Only two documents (12\%) gave some instructions on how to safely transport food from outside and within the ETU to the patients. Almost two-thirds provided instructions on leftover food and utensils retrieval from the patients' bed sites.

\section{Patient's preferences}

Various materials covered some guidance on how to assess or accommodate patients' dietary preferences (41\%) or how to obtain feedback on nutritional care from patients within ETU (18\%).

\section{Malnutrition, antbropometry and discharge}

Many materials ( $71 \%$ ) contained guidance on if, when and how to conduct anthropometric measurements; most only advised the use of these measurements at time of discharge. Two-thirds had some instructions on discharge procedures and food provision for recovery for discharged patients.

Guidance materials provided by Save the Children and the Ministry of Health and Social Welfare from Liberia were the most comprehensive, followed by the pocket guide for the frontline health worker from $\mathrm{WHO}^{(10,14,20)}$. These materials addressed approximately $60-73 \%$ of the listed topics and provided therefore relatively more guidance on the nutritional care for patients in ETU. There were no substantial differences between older (2014-2017) and more recent (2018-2019) developed guidance materials.

\section{Discussion}

This is the first study to analyse guidance materials on nutritional care for EVD issued since 2014 by non-governmental organisations, the Red Cross/Red Crescent Movement, governments and UN agencies. Though an earlier investigation among practitioners ${ }^{(2)}$ showed the need for increased inclusion of local food products in the patients' diets, especially for adults, very few of the studied guidance documents stressed the importance of, or instructed on the inclusion of local foods. Similarly, earlier investigation among practitioners also noted absence of guidance on how to organise a food system within an ETU (e.g. how to organise patients' diets, transfer of food to patients, planning of supplies concerning the number of patients) in the 2014 Interim Guidelines ${ }^{(2,3)}$. While these specific issues were largely absent in the currently reviewed documentation, some governmental, non-governmental organisations and Red Cross/Red Crescent documents included some details related to food preparation and distribution. One aspect, which includes retrieval of left-over food, is particularly important because of the highly infectious environment in the context of EVD. Minimising the volume of contaminated left-over food stresses the importance of accommodating patients' dietary preferences and feedback on the nutritional care. It is striking that these last two topics were poorly covered in most guidance materials.

Feeding support to very sick and/or paediatric patients in ETU is paramount and instructions on how to assess the individual need was mostly lacking, though guidance on how to provide the support was occasionally included. Most guidance did not mention anthropometric measurements 
at admission of patients in ETU. Though speculative, this might be due to workload upon admission in an ETU for health care workers and the condition of malnutrition might possibly be perceived as a lower medical priority. Yet, it is widely known that malnutrition as co-morbidity in any infectious disease, including EVD, or in patients who are critically ill, will jeopardise response to treatment ${ }^{(22-25)}$.

Night-time feeding was mentioned in few guidance materials but can be important during an EVD outbreak, especially in warmer climates ${ }^{(2)}$. In the West Africa outbreak, patients were sometimes more alert due to cooler temperatures, and therefore appetite was higher. Eating during night-time contributed to fulfilling the energetic needs, particularly of convalescent patients. Three out of seventeen documents included some advice on how to make, for example, ORS or corn soy blend more palatable or acceptable. This aspect is particularly important for ORS as it might increase the uptake, especially when commercially flavoured ORS is offered ${ }^{(14,26)}$. Guidance on the use of juices and sugary/carbonated drinks was contradictory. However, some practitioners have advocated for their usefulness in increasing fluid intake despite their high osmolarity potentially aggravating diarrhoea ${ }^{(2,4)}$.

Before 2014, limited literature was available on nutritional care of EVD patients. Practitioners encountered difficulties in finding the most appropriate approach ${ }^{(2,27)}$, and organisations and governments developed their own guidance in the absence of a solid scientific base ${ }^{(2)}$. Care for EVD patients is complex because of its highly infectious character, the specific symptoms interfering with patients' ability to eat, the severity of the pathology, the treatment in relatively low resourced contexts and limited possibilities for relatives to feed the patients ${ }^{(2)}$. This combination requires comprehensive guidance for organisations and governments that provide nutritional care in ETU compared with other diseases. Such guidance should include topics, such as the nutritional assessment of patients with EVD, the general management, diet and feeding of children and adults with EVD, nutrients that need specific attention during treatment, symptoms affecting the patient's nutritional care and status, the organisation of the food and distribution system in and around an ETU, the organisation of anthropometric measurements, and how to address patients' dietary preferences.

This analysis shows that substantial guidance materials have been developed covering a wide range of relevant topics. Although every EVD outbreak response must be contextualised because of the complexity of EVD and its case management, it is important to work towards consolidation of the various guidance materials. Therefore, it is essential to resolve potential technical differences (e.g. on use of naso-gastric tube, choice of oral intake of fluids other than ORS) and to provide improved, comprehensive, consistent and practical guidance. The findings of this study include a comprehensive list of topics, which may inform the future revised guidelines from normative UN organisations and governments of countries affected by EVD.

\section{Limitations}

Only thirteen organisations and governments were included in this review; therefore not all guidance materials developed since 2014 were included. However, guidance materials from most major organisations and governments involved in the response were analysed.

\section{Conclusion}

Since 2014, numerous materials have been developed by organisations and governments on nutritional support in ETU for adults and children. Though scientific evidence on the most appropriate nutritional care is still lacking, there is a need for improved, comprehensive, consistent and operational guidance.

\section{Acknowledgements}

Acknowledgements: Not applicable. Financial support: No additional sources for funding. This study was done as regular work under CDC (M.V.) and as a student (C.V.). Conflict of interest: None. Authorship: M.V. initiated the study and collected the guidance materials. M.V. and C.V. conducted the analyses of all guidance materials. M.V. wrote the manuscript. Ethics of buman subject participation: Not applicable.

\section{Supplementary material}

For supplementary material accompanying this paper visit https://doi.org/10.1017/S136898002000261X

\section{References}

1. Centers for Disease Control and Prevention (2018) Eastern Democratic Republic of the Congo Outbreak (ongoing) https://www.cdc.gov/vhf/ebola/outbreaks/drc/2018-august. html (accessed July 2019).

2. Ververs M \& Anantharam P (2019) Nutritional care for patients with Ebola virus disease in Ebola treatment units past and current experiences from practitioners. Int J Nutr 4, 9-29.

3. WHO, UNICEF \& WFP (2014) Interim Guideline: Nutritional Care of Children and Adults with Ebola Virus Disease in Treatment Centres. Interim Guideline. Geneva: World Health Organization; available at https://www.who.int/ nutrition/publications/guidelines/nutritionalcare_with_ebolavirus/ en/ (accessed June 2019). 
4. Ververs M \& Gabra M (2020) Nutritional care for patients with Ebola virus disease. Emerg Infect Dis 26, 20-25

5. International Medical Corps (2014) Nutritional Guidelines for Ebola Treatment Centers. pp. 1-3.

6. GOAL (2014) International Package of Various Tools/ Protocols for ETU. Port Loko Ebola Treatment Center.

7. International Committee of the Red Cross (2015) Nutrition Care Protocols for Ebola Virus Disease (EVD) Patients Liberia experience.

8. International Federation of Red Cross and Red Crescent Societies (2015) Ebola Treatment Center Standard Operating Procedures.

9. Partners in Health (2015) Nutritional Care for Patients at Maforki Ebola Holding and Treatment Centre.

10. Save the Children (2015) Kerrytown Ebola Treatment Centre. ETC Nutrition Protocol.

11. International Committee of the Red Cross and Médecins Sans Frontières (2016) Nutritional protocol for patients infected with Ebola Virus Disease.

12. Médecins Sans Frontières International (2018) Appendix: Nutritional Tools for Patients Infected with Filovirus Disease (FVD). 2018 Filovirus Disease Guidelines.

13. Government of Sierra Leone. Sierra Leone Emergency Management Program Standard Operating Procedure for Food Distribution to Quarantined Households, Holding and Treatment Centres. Sierra Leone Emergency Management Program Standard Operating Procedure for Nutritional Support, Version (1), pp. 1-27.

14. Ministry of Health and Social Welfare, Republic of Liberia (2014) Guidelines on Nutritional Care and Support for EVD Patients in Treatment Units and Care Centers. A Practical Guide for Implementing Agencies Involved in the Management and Treatment of EVD in Liberia, pp. 1-45.

15. Ministry of Health and Social Welfare, Republic of Liberia (2014) Guideline for Ebola Virus Disease Outbreak in Affected Countries of Liberia on Infant and Young Child Feeding in an Emergency. Guidelines in the context of Ebola Virus Disease Outbreak in Affected Countries of Liberia, pp. 1-27.

16. Ministry of Health - WHO by PRONANUT with the support of UNICEF and WFP (2018) Joint Nutritional and Food Management Strategy without the Ebola Virus Disease Epidemic Response Framework in the Health Zones of Bikoro, Iboko, Ntondo, Mbandaka and Wanganta in the Equateur Province, DRC. For the Ebola Virus Disease Response Strategy, pp. 1-8.

17. PRONANUT National Nutrition Programme at the Ministry of Health with the support of UNICEF-DRC (2018) Guidance
Manual on the Promotion, Protection and Support of Infant and Young Child Feeding in Community Settings, in the Context of the Ebola Virus Disease Epidemic, pp. 1-25.

18. Democratic Republic of Congo Ministry of Health National Nutrition Programme with the support of UNICEF-DRC, adapted from WHO (2018) Protocol for Nutritional Care for Adults and Children with Ebola Virus Disease Hospitalized in Treatment Centres (ETC), pp. 1-17.

19. UNICEF. Food and nutrition component of direct EVD Response - Liberia, Guinea, Sierra Leone. Date unknown.

20. WHO (2016) Clinical management of patients with viral haemorrhagic fever. A pocket guide for the front-line health worker, pp. 1-203; available at https://www.who.int/csr/ resources/publications/clinical-management-patients/en/ (accessed June 2019).

21. WHO (2019) Optimized Supportive Care for Ebola Virus Disease. Clinical Management Standard Operating Procedures, pp. 21; available at https://www.who.int/csr/ resources/publications/optimized-supportive-care/en/ (accessed June 2019).

22. Smit MA, Michelow IC, Glavis-Bloom J et al. (2017) Characteristics and outcomes of pediatric patients with Ebola virus disease admitted to treatment units in Liberia and Sierra Leone: a retrospective cohort study. Clin Infect Dis 64, 243-249.

23. Uyeki TM, Mehta AK, Davey RT Jr et al. (2016) Working group of the U.S.-European clinical network on clinical management of Ebola virus disease patients in the U.S. and Europe. clinical management of Ebola virus disease in the United States and Europe. $N$ Engl J Med 374, 636-646.

24. McClave SA, Taylor BE, Martindale RG et al. (2016) Society of critical care medicine; American Society for Parenteral and Enteral Nutrition. Guidelines for the provision and assessment of nutrition support therapy in the adult critically ill patient. JPEN J Parenter Enteral Nutr 40, 159-211.

25. Mehta NM, Skillman HE, Irving SY et al. (2017) Guidelines for the provision and assessment of nutrition support therapy in the pediatric critically ill patient. JPENJ Parenter Enteral Nutr 41, 706-742.

26. te Loo DM, van der Graaf F \& Ten WT (2004) The effect of flavoring oral rehydration solution on its composition and palatability. J Pediatr Gastroenterol Nutr 39, 545-548.

27. Kodish SR, Rohner F, Beauliere JM et al. (2018) Implications of the Ebola virus disease outbreak in Guinea: qualitative findings to inform future health and nutrition-related responses. PLoS One. Published online: 23 August 2018. doi: 10.1371 /journal.pone.0202468. 